\title{
Gambaran kasus asfiksia mekanik di Bagian Forensik RSUP Prof. Dr. R.D. Kandou periode tahun 2010 -2015
}

\author{
${ }^{1}$ Marisna Robi \\ ${ }^{2}$ James F. Siwu \\ ${ }^{2}$ Erwin G. Kristanto
}

${ }^{1}$ Kandidat Skripsi Fakultas Kedokteran Universitas Sam Ratulangi Manado
${ }^{2}$ Bagian Ilmu Kedokteran Forensik Medikolegal Fakultas Kedokteran
Universitas Sam Ratulangi Manado
Email: marisnarobi@yahoo.co.id

\begin{abstract}
Asphyxia is a condition characterized by the disturbance of gas exchange in the respiratory tract resulted in reduced oxygen accompanied by increased carbon dioxide in the blood. Mechanical asphyxia is suffocation that occurs when the airway was obstructed by various circumstances (which are mechanical), as follows: choking, smothering, strangulation by ligature, manual strangulation, and hanging. This study was aimed to obtain the profile of mechanical asphyxia cases at Forensic Department of Prof. Dr. R. D. Kandou Hospital period 2010-2015. This was a descriptive retrospective study. The results of the external examination and autopsy showed that there were 22 cases of death due to mechanical asphyxia. The highest percentage of asphyxia cases was in 2011 as many as 8 cases $(36.5 \%)$. Most cases were in the age group of $17-25$ years old (7 cases; $31.8 \%)$. Males (12 cases; $54.5 \%)$ were slightly more frequent than females (10 cases; 45.5\%). The most cases of mechanical asphyxia were hanging (15 cases; $68.2 \%$ ). The most common sign of asphyxia was congestion of the organs (19 cases; $86.4 \%$ ).
\end{abstract}

Keywords: asphyxia, mechanical asphyxia, forensic

\begin{abstract}
Abstrak: Asfiksia adalah suatu keadaan yang ditandai dengan terjadinya gangguan pertukaran udara dalam saluran pernapasan yang berakibat menurunnya oksigen dalam darah berkurang disertai dengan meningkatnya karbon dioksida. Asfiksia mekanik adalah mati lemas yang terjadi bila udara pernapasan terhalang memasuki saluran pernapasan oleh berbagai kekerasan (bersifat mekanik), yaitu pembekapan, penyumpalan, jeratan, cekikan dan gantung. Penelitian ini bertujuan untuk mengetahui gambaran kasus asfiksia mekanik di Bagian Forensik RSUP Prof. Dr. R. D. Kandou periode tahun 2010-2015. Jenis penelitian ialah deskriptif retrospektif menggunakan data hasil pemeriksaan luar dan autopsi. Hasil penelitian mendapatkan 22 kasus kematian akibat asfiksia mekanik. Kasus terbanyak pada tahun 2011 yaitu 8 kasus $(36,5 \%)$. Kelompok usia terbanyak ialah 17-25 tahun dengan 7 kasus $(31,8 \%)$. Jenis kelamin laki-laki sedikit lebih banyak yaitu 12 kasus (54,5\%) dibandingkan perempuan yaitu 10 kasus $(45,5 \%)$. Kasus asfiksia mekanik tersering ialah gantung dengan jumlah 15 kasus $(68,2 \%)$. Tanda asfiksia yang sering ditemukan ialah pembendungan organ dalam yaitu 19 kasus $(86,4 \%)$.
\end{abstract}

Kata kunci: asfiksia, asfiksia mekanik, forensik

Asfiksia adalah keadaan dimana oksigen $\left(\mathrm{O}_{2}\right)$ dalam darah berkurang yang disertai peningkatan kadar karbondioksida $\left(\mathrm{CO}_{2}\right)$. Hal tersebut berhubungan dengan terjadinya obstruksi (sumbatan) pada saluran pernapasan atau gangguan yang diakibatkan karena terhentinya sirkulasi. Gagasan umum dari asfiksia adalah gangguan mekanis yang 
menghalangi pernapasan. Asfiksia merupakan salah satu kasus penyebab kematian terbanyak yang ditemukan dalam kasus kedokteran forensik. ${ }^{1}$

Menurut Centers for Disease Control (CDC) dari database kasus kematian 19992004, berdasarkan sertifikat kematian penduduk Amerika Serikat didapatkan sekitar 20.000 kasus kematian disengaja maupun tidak, dalam jangka waktu berkaitan dengan berbagai jenis kasus tipe asfiksia mekanik: tenggelam, gantung diri, jeratan, dan pembekapan. Penyebab paling umum kematian berbeda antara kelompok usia. Kasus tenggelam mayoritas sering terjadi pada kelompok usia 1-4 tahun, sedangkan gantung diri, jeratan dan tenggelam paling umum di kelompok usia 35-44 tahun. ${ }^{2}$

Salah satu studi yang dilakukan di Rumah Sakit Umum Citradurga India pada periode 1 Januari 2012-31 Desember 2012 melalui rekam medik melaporkan bahwa dari 343 kasus autopsi terdapat 36 kematian akibat asfiksia mekanik (10,50\%). Yang paling sering ditemukan ialah kematian yang disebabkan oleh gantung diri $(80,60 \%)$ diikuti kematian akibat tenggelam $(8,30 \%)$. Kematian akibat jeratan $(5,50 \%)$ ditemukan lebih banyak daripada kematian akibat traumatis $(2,80 \%)$. Dari data yang dikumpulkan, ditemukan bahwa kelompok usia 21-30 tahun paling rentan terhadap kematian asfiksia yang bersifat kekerasan, diikuti kelompok usia 31-40 tahun. Juga didapatkan kasus pada laki-laki (75\%) lebih banyak daripada perempuan $(25 \%){ }^{3}$

Pada hasil penelitian di Instalasi Kedokteran Forensik RSUP Dr. Sardjito tahun 2007-2012 diperoleh 72 kasus kematian akibat asfiksia mekanik dari total rekam medis berjumlah 904. Subjek berjenis kelamin laki-laki memiliki prevalensi lebih besar yaitu 48 korban (64\%). Prevalensi kelompok usia 21-40 tahun merupakan yang tertinggi yaitu 35 kasus $(46,47 \%)$. Kasus terbanyak ialah kasus obstruksi jalan nafas oleh benda asing sebanyak 32 kasus (42,67\%). Prevalensi terbanyak kasus yang ditemukan memiliki ciri yang sama pada kasus bunuh diri sebanyak 27 kasus $(36 \%){ }^{4}$

Penelitian ini bertujuan untuk mengetahui gambaran umum tentang kasus asfiksia mekanik di Bagian Forensik RSUP Prof. Dr. R. D. Kandou.

\section{METODE PENELITIAN}

Jenis penelitian ini ialah deskriptif retrospektif. Sampel yang diambil ialah kasus asfiksia mekanik di Bagian Forensik RSUP Prof. Dr. R D. Kandou pada periode tahun 2010 sampai dengan tahun 2015.

Variabel penelitian yang diteliti yaitu: jumlah kasus asfiksia mekanik per tahun, usia, jenis kelamin, jenis asfiksia mekanik dan tanda-tanda asfiksia yang ditemukan pada jenazah

\section{HASIL PENELITIAN}

Pengumpulan data hasil autopsi dan pemeriksaan luar dilakukan sejak 10 Oktober sampai 27 Oktober 2016 di Bagian Kedokteran Forensik RSUP Prof. Dr. R D. Kandou. Selama periode penelitian 2010 sampai 2015, terdapat kasus kematian yang diakibatkan oleh asfiksia mekanik sebanyak 22 kasus.

Tabel 1 memperlihatkan jumlah kasus asfiksia mekanik per tahun sesuai periode penelitian 2010 sampai 2015. Kasus terbanyak terjadi pada tahun 2011 sebanyak 8 kasus (32\%).

Tabel 1. Jumlah kasus asfiksia mekanik per tahun

\begin{tabular}{ccc}
\hline Tahun & Jumlah kasus & $\mathbf{( \% )}$ \\
\hline 2010 & 1 & 4.5 \\
2011 & 8 & 36.5 \\
2012 & 3 & 13.6 \\
2013 & 3 & 13.6 \\
2014 & 4 & 18.2 \\
2015 & 3 & 13.6 \\
Total & 22 & 100 \\
\hline
\end{tabular}

Tabel 2 memperlihatkan kematian yang disebabkan oleh asfiksia mekanik menurut kelompok usia ditemukan tertinggi ditemukan pada kelompok usia 17-25 tahun dengan 7 kasus (31.8\%). 
Tabel 2. Distribusi kasus menurut usia

\begin{tabular}{ccc}
\hline $\begin{array}{c}\text { Kategori usia } \\
\text { (Tahun) }\end{array}$ & Jumlah & $(\boldsymbol{\%})$ \\
\hline $0-5$ & 0 & 0 \\
$6-11$ & 2 & 9,1 \\
$12-16$ & 2 & 9,1 \\
$17-25$ & 7 & 31,8 \\
$26-35$ & 6 & 27,3 \\
$36-45$ & 2 & 9,1 \\
$46-55$ & 2 & 9,1 \\
$56-65$ & 0 & 0 \\
$>65$ & 1 & 4,5 \\
Total & 22 & 100 \\
\hline
\end{tabular}

Tabel 3 menunjukkan bahwa kasus kematian akibat asfiksia mekanis pada lakilaki $(54,5 \%)$ dan perempuan $(45,5 \%)$ tidak berbeda banyak.

Tabel 3. Distribusi kasus menurut jenis kelamin

\begin{tabular}{ccc}
\hline Jenis kelamin & Jumlah & $\mathbf{( \% )}$ \\
\hline Laki-laki & 12 & 54.5 \\
Perempuan & 10 & 45.5 \\
Total & 22 & 100 \\
\hline
\end{tabular}

Pada Tabel 4 terlihat distribusi kasus kematian dengan asfiksia mekanik menurut jenis asfiksia mekanik didapatkan kasus gantung paling banyak yaitu 15 kasus $(68,2 \%)$

Tabel 4. Distribusi kasus menurut jenis asfiksia mekanik

\begin{tabular}{ccc}
\hline $\begin{array}{c}\text { Jenis } \\
\text { asfiksia mekanik }\end{array}$ & Jumlah & $(\boldsymbol{\%})$ \\
\hline Gantung & 15 & 68,2 \\
Jeratan & 2 & 9,1 \\
Cekikan & 4 & 18,2 \\
Pembekapan & 1 & 4,5 \\
Penyumpalan & 0 & 0 \\
Total & 22 & 100 \\
\hline
\end{tabular}

Tabel 5 menunjukkan bahwa tanda yang sering dtemukan pada kasus kematian dengan asfiksia yaitu pembendungan organ dalam sebanyak 19 dari 22 kasus $(86,4 \%)$.
Tabel 5. Tanda-tanda asfiksia yang ditemukan pada jenazah

\begin{tabular}{lcc}
\hline $\begin{array}{c}\text { Tanda-tanda pada } \\
\text { jenazah }\end{array}$ & $\begin{array}{c}\text { Jumlah } \\
\text { kasus }\end{array}$ & $\mathbf{( \% )}$ \\
\hline $\begin{array}{l}\text { Sianosis } \\
\text { Petekie (tardieu's } \\
\text { spot) pada mata }\end{array}$ & 1 & 31,8 \\
$\begin{array}{l}\text { Busa halus pada } \\
\text { saluran pernapasan }\end{array}$ & 4 & 18,2 \\
$\begin{array}{l}\text { Perdarahan berbintik } \\
\text { pada organ dalam }\end{array}$ & 10 & 45,5 \\
$\begin{array}{l}\text { Pembendungan } \\
\text { organ dalam }\end{array}$ & 19 & 86,4 \\
\hline
\end{tabular}

\section{BAHASAN}

Sebuah studi penelitian di Departemen Kedokteran Forensik dan Toksikologi Lokmanya Tilak Munici - Medical College \& Hospital, Sion, Mumbai selama Agustus 2012 sampai Juli 2014 menyelidiki profil demografi sosial, penyebab, dan cara kematian asfiksia pada wanita. Pada penelitian tersebut didapatkan 55 kasus dengan kasus terbanyak pada usia 14-25 tahun yaitu 34 kasus $(61,8 \%)$. Menurut tingkat pendidikan ditemukan tingkat pendidikan menengah dengan 13 kasus (23,6\%), pekerjaan ibu rumah tangga 29 kasus (52.7\%), dengan usia waktu menikah antara 6-10 tahun 14 kasus $(43,74 \%)$ dan sebagian besar penyebab kematian ialah bunuh diri dengan cara gantung diri dan kasus terbanyak pada bulan Okotober sampai Desember sejumlah 19 kasus $(34,44 \%){ }^{5}$

Penelitian yang membahas mengenai analisis kematian asfiksia akibat gantung yang dilakukan di Fakultas Kedokteran dan rumah sakit di Mumbai pada periode 1 Januari sampai 31 Desember 2012 mendapatkan sebanyak 60 kasus dari hasil pemeriksaan autopsi dan pemeriksaan luar. Tanda yang sering pada kematian akibat asfiksia dengan kasus gantung yaitu bintik perdarahan $48(80 \%)$ kasus dan sianosis 17 kasus (28\%) sedangkan fraktur pada os hyoid dan os thyroid hanya 5 kasus $(8,3 \%){ }^{6}$

Penelitian yang dilakukan oleh Patel et al. ${ }^{7}$ di Departemen Kedokteran Forensik, M. P. Shah Fakultas Kedokteran Jamnagar, 
mengenai kematian akibat penekanan pada leher dengan jeratan dilakukan sejak Oktober 2010 sampai Agustus 2012 dengan total 100 kasus. Kejadian tertinggi pada kelompok usia 21-30 tahun (35\%). Tanda yang sering ditemukan pada jenazah yaitu sianosis pada ujung jari dengan 68 kasus yaitu 66 kasus pada gantung dan 2 kasus pada jeratan.

Laporan kasus mengenai pembunuhan seorang bayi perempuan yang ditemukan di tempat pembuangan di Sofia mendapatkan pada pemeriksaan luar ditemukan tandatanda luka lecet pada seluruh tubuh korban, bintik perdarahan terlihat pada konjungtiva di kedua mata dan pada sisi kanan leher ditemukan adanya memar kebiruan. Pada autopsi ditemukan, kepala bagian frontal dan parietal terlihat udem jaringan lunak dan fraktur tulang tengkorak. Bagian leher terlihat adanya edema jaringan lunak sesuai dengan tanda yang ditemukan pada pemeriksaan luar dan terdapat bintik perdarahan di bawah epikandrium. ${ }^{8}$

Kasus kematian akibat benda asing dalam saluran pernapasan ( penyumpalan/ tersedak, choking), pernah dilaporkan mengenai seorang anak perempuan berusia 13 tahun tersedak karena meminum minuman buah yang menyebabkan aspirasi dan kemudian meninggal. Hasil pemeriksaan autopsi mendapatkan kongesti paru yang hebat, adanya busa-busa halus pada saluran pernapasan, petekie pada permukaan paru-paru, sub-plura dan subepikardial. Pada pembedahan trakea ditemukan adanya cairan atau mukus yang berwarna oranje dan banyak busa halus pada lumen. $^{9}$

Sebuah studi kasus melaporkan korban seorang laki-laki muda berusia 27 tahun yang bekerja sebagai instruktur gym, ditemukan di antara semak-semak oleh polisi yang sedang melakukan patroli di daerah Haryana. Pada pemeriksaan luar ditemukan mulut mayat ditutupi dengan selotip putih, leher dililiti selotip putih, kedua tangan bersilangan dibagian belakang dan kedua pergelangan kaki terikat dengan selotip putih. Terdapat luka memar pada daerah wajah terutama pada daerah bibir. Pada pemeriksaan dalam didapatkan kongesti organ dalam pada paru-paru, hati dan ginjal. Petekie terdapat pada regio temporal kiri, vertebra, faring, dan esofagus sedangkan tulang rawan lidah tampak dalam keadaan utuh. ${ }^{10}$

Dari perbandingan hasil penelitian ini dan penelitian sebelumnya, terlihat jelas perbedaan yang berhubungan dengan jumlah kasus dimana kemungkinan ini menyangkut jumlah populasi, kebudayaan dan kebiasaan hidup tiap daerah. Mengenai jenis kelamin, laki-laki memiliki tingkat kejadian paling tinggi. Pada kategori usia, hampir semua penelitian menunjukkan rata - rata usia yang paling sering terjadi pada kategori ialah 15-30 tahun. Kasus kamatian dengan asfiksia mekanik paling sering ditemukan pada kasus dengan gantung. Tanda yang paling sering ditemukan pada pemeriksaan yaitu kongesti (pembendungan) pada organ dalam, busa halus pada saluran pernapasan dan bintik-bintik perdarahan baik pada pemeriksaan luar maupun pemeriksaan dalam.

\section{SIMPULAN}

Berdasarkan hasil penelitian ini dapat disimpulkan bahwa prevalensi terjadinya kasus kematian yang disebabkan oleh asfiksia mekanik terbanyak pada tahun 2011, kelompok usia 17-25 tahun, jenis kelamin laki-laki, asfiksia mekanik dengan cara gantung, dan tanda-tanda pada jenazah berupa kongesti (pembendungan) organ dalam.

\section{SARAN}

1. Bagi peneliti lanjut agar menggunakan jumlah sampel yang lebih besar dengan jangkauan pengambilan data yang lebih luas. Selain itu juga bisa dilakukan penelitian dengan analisis untuk mencari hubungan antar variabel.

2. Bagi aparat kepolisian agar menjadi referensi dalam menangani kasus asfiksia baik pada saat melakukan penyelidikan di TKP maupun dalam tindak peradilan. 


\section{DAFTAR PUSTAKA}

1. Idries AM. Pedoman Ilmu Kedokteran Forensik (1st ed). Jakarta: Binarupa Aksara, 1997.

2. Michael AG, Denton JS, editors. Pathology of Asphyxial Death. Epidemiolgy. [Online]. 2016 [cited Sept 2016]. Available from: http://emedicine.medscape.com/articl e/1988699-overview\#a1

3. Ajay KS, Chandan V, Rudresh VY, Govindaraju HC, Gouda S. Study of violent asphyxia deaths in Chitradurga district of Karnataka. IJBAR. 2013;4(12):868-71.

4. Prabowo KN. Gambaran kasus asfiksia mekanik yang ditangani di Instalasi Kedokteran Forensik RSUP Dr. Sardjito Tahun 2007-2012. Gadjah Mada University [Online]. 2013 [cited Sept 2016]. Available from: http://etd.repository.ugm.ac.id/index. php?mod=penelitian_detail\&sub=Pen elitianDetail\&act=view \&typ=html\&b uku_id=62982

5. Dhoble SV, Dhoble SS, Kukde HG. Socio- demographic profile of asphyxial deaths in female $2 \mathrm{yr}$ study. IJSR. 2016;5(2):51-4.

6. Waghmare PB, Chikhalkar BG, Nanandkar SD. Analysis of asphyxial deaths due to hanging. J Indian Acad Forensic Med. 2014;36(4):343-5.

7. Patel JB, Bambhaniya AB, Chaudhari KR, Upadhyay MC. Study of death due to compression of neck by ligature. IJHSR. 2015;5:76-81.

8. Nikolov D, Michich IB, Goshev M, Alexandrov A, Hristov S. A case of neonaticide - manual strangulation of a newborn. Medicine. 2015;5(1):3103.

9. Sharma L, Sirohiwal BL, Paliwal PK. Choking due to fruit drink aaspiration. Forensic Medicine and Anatomy Research. 2013;1(1):1-3.

10.Chhikara $P$, Dhattarwal SK, Merry $V$, Kumar V, Gaurav S, Giri S. Bound, murdered \& disposed - a case report. Int Med Soc Sci. 2016;1:130-3. 